Canadian

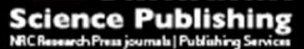

Canadian Journal of Civil Engineering Revue canadienne de génie civil

\title{
Experimental Observation of Saline Underflows and Turbidity Currents, Flowing over Rough Beds
}

\begin{tabular}{|r|l|}
\hline Journal: & Canadian Journal of Civil Engineering \\
\hline Manuscript ID & cjce-2014-0537.R1 \\
\hline Danuscript Type: & Article \\
\hline Complete List of Authors: & $\begin{array}{l}\text { Varjavand, Peyman; University of Tabriz, Department of Water Engineering } \\
\text { Ghomeshi, Mehdi; Shahid Chamran University of Ahwaz, Faculty of Water } \\
\text { Science Engineering } \\
\text { Hosseinzadeh Dalir, Ali; University of Tabriz, Department of Water } \\
\text { Engineering } \\
\text { Farsadizadeh, Davood; University of Tabriz, Department of Water } \\
\text { Engineering } \\
\text { Docheshmeh Gorgij, Alireza; University of Tabriz, Faculty of Science }\end{array}$ \\
\hline Keyword: & $\begin{array}{l}\text { Entrainment coefficient, Lifting phenomenon, Saline density current, } \\
\text { Sediment-laden density current, Velocity profile }\end{array}$ \\
\hline & \\
\hline
\end{tabular}

SCHOLARONE $^{\text {m }}$

Manuscripts 


\title{
Experimental Observation of Saline Underflows and Turbidity Currents, Flowing over Rough Beds
}

\author{
Peyman Varjavand ${ }^{1}$ \\ Ph.D of Hydraulic Engineering \\ pvarjavand@yahoo.com \\ $+989168445321$ \\ Mehdi Ghomeshi \\ Professor, Faculty of Water Science Engineering, Shahid Chamran University of \\ Ahwaz, Ahwaz, Iran \\ m.ghomeshi@yahoo.com
}

\begin{abstract}
Ali Hosseinzadeh Dalir
Professor, Department of Water Engineering, University of Tabriz, Tabriz, Iran

ahdalir1@yahoo.co.uk
\end{abstract}

Davood Farsadizadeh

Associated professor, Department of Water Engineering, University of Tabriz, Tabriz, Iran

farsadid@yahoo.com

Alireza Docheshmeh Gorgij

Ph.D candidate of Hydrogeology, Faculty of Science, University of Tabriz, Tabriz, Iran a.gorgij@gmail.com

\footnotetext{
${ }^{1}$ Corresponding author
} 


\begin{abstract}
Density currents are formed when gravity acts upon a density difference between two different fluids, and the driving force is the buoyancy force. These currents are the most important transport mechanisms and deposition of noncohesive sediments in narrow and deep reservoirs. In this research, 126 experiments were performed to investigate the effects of artificial bed roughness on saline and sediment-laden density currents. Conic and cylindrical shapes of roughness were used with three different heights. Velocity and concentration profiles were measured in 4 and 3 cross-sections, respectively. Presence of roughness causes increasing density current body thickness, decreasing maximum value of velocity and increasing distance of peak value of velocity point from the bed in the normal velocity profile. Coefficient of entrainment in the rough beds was more than smooth bed and boosted for greater roughness heights. A special behavior, named as "Lifting phenomenon", was appeared in some of the tests which effects on the velocity profiles.
\end{abstract}

Keywords: Entrainment coefficient, Lifting phenomenon, Saline density current, Sediment-laden density current, Turbidity current, Velocity profile

\title{
Introduction
}

Density currents can be observed in natural and artificial phenomena (Simpson 1982). When a high density buoyant inflow enters to an ambient fluid, it sinks below and forming an underflow. This flow is progressively diluted due to fluid entrainment and it is the main process for the transport and deposit of sediments in reservoirs (Bournet et al. 1999).

Through years, many researches were conducted to determine the factors affecting the regime of density currents. Previous laboratory experiments include such as Ellison and Turner (1959), Garcia and Parker (1993) and Altinakar et al. (1996). Some researchers have focused on stopping turbidity currents in reservoir such as Linden and Simpson (1986), Toniolo et al. (2007) and Oehy et al. (2010). Finite number of experimental studies focused on geomorphic implication of density flows, for example, Imran et al. (2004), Islam and Imran (2008) and Ezz et al. (2013). 
Topography plays an important role in the dynamics of turbidity currents and inevitably their deposits are affected in natural settings. Kubo (2004) has investigated the topographic influences on sedimentation from particle-driven density currents for ramp and hump topography. Results have shown that the preferential deposition downstream of the slope break is interpreted as a result from deceleration of the flow, which increases deposit distribution through loss of capacity of the flow and longer duration of the flow passage. Sequeiros et al. (2010) explored the effects of bed natural roughness and bed forms on the vertical profiles of velocity and fractional excess density of the currents. They observed four types of bed form, can be seen in subcritical flows (dunes) and supercritical flows (UMAs and DMAs). Over the plan bed, peak of velocity in the subcritical flows velocity profile are tended toward the interface between the flow and the ambient water regardless of bed type which is in contrary to the supercritical flows. With no bed forms, supercritical flows result profiles of fractional excess density that decline smoothly in the upward direction. For subcritical flows, fractional excess density tends to be relatively constant until some point below the interface. For supercritical flows, the influence of bed forms is particularly stronger than subcritical flows. They were calculated shape factors for velocity profiles for different flow and bed forms. Normalized velocity profiles for supercritical flows scaled up well with observations of field-scale turbidity currents in the Monterey Canyon. Oshaghi et al. (2013) performed a series of laboratories experiments with various obstacle heights and different inlet densimetric Froude numbers. Their results showed that the current with lower inlet Froude number reacts more rapidly to the obstacle, compared with higher Froude number current. They observed that increasing in the height of the obstacle results declining the flow inertia, decreasing the maximum velocity and the local Froude number consequently. They reported that the current had a significant increase in its mean velocity while passing over the obstacle causing an intense increase in local Froude number just over the obstacle. Higher obstacles have more effect on the current and thus its characteristics varies more intensely.

The present work explores the effect of artificial bed roughness on the saline and sedimentladen density currents. Based on done reviews, ever, response of density currents to artificial rough bed has not been investigated. Interesting results have been obtained which will be analyzed in the next sections. In following sections, we describe methods followed by experimental results, discussion and conclusion. 


\section{Experimental Setup}

The experiments were conducted in Laboratory of Physical and Hydraulic Models, Shahid Chamran University of Ahwaz, Iran. A straight channel with $8 \mathrm{~m}$ long, $0.35 \mathrm{~m}$ wide and 0.70 $\mathrm{m}$ height was used. The tilting flume was divided into two longitudinal sections using a separating Plexiglas sheet. The shorter upstream section accumulated dense fluid with a sluice gate in rectangular bottom and a reticulated Plexiglas sheet reduced its turbulence in this section. The adjustable opening allowed changing the inlet velocity of dense fluid. The opening heights were 50 and $100 \mathrm{~mm}$ for saline and sediment-laden density currents, respectively, in all tests. The size of the opening was determined by trial and error method to achieve uniform flow in $1.5 \mathrm{~m}$ downstream of sluice gate. The roughness elements have been installed from $1.5 \mathrm{~m}$ to $5.5 \mathrm{~m}$ downstream of sluice gate. The flume was filled with fresh water (ambient fluid) previously. Its maximum temperature difference with dense fluid was $\pm 0.5^{\circ} \mathrm{c}$ in all tests. Hence an over fall spillway assured a constant ambient fluid level during experiments, the ambient fluid depth varied between 59 to 67 centimeters at the downstream of the rough bed because of its slope. A typical test lasted for $1200 \mathrm{~s}$ during that velocity and concentration profiles were recorded. At start of the test, the dense fluid continuously left the accumulator through the gate flowing down the sloping bottom. The saline and sedimentladen density currents gradually spread under the fresh water. At the flume end, the dense fluid was withdrawn through the bottom drain.

A tank, called the mixing tank, with a maximum capacity of $3 \mathrm{~m}^{3}$, was used to prepare the dense fluid mixture. A supplying pipe fed the dense fluid from the mixing tank to overhead tank which is installed $3 \mathrm{~m}$ from ground with a maximum capacity of 625 liters. This tank equipped by and overflow weir to keep the dense fluid head constant and to prevent the influence of fluctuations in overhead tank on the feed rate. A valve was controlling the feed rate, from overhead tank to flume, measured by an electromagnetic flowmeter of $\pm 0.005 \mathrm{~L} / \mathrm{s}$ accuracy.

Two types of bottom-hugging density flows were studied: 63 experiments which obtained their driving force from suspended sediments and 63 experiments which obtain their driving force from dissolved salt. The fine suspended sediment consist of kaolin with specific density of $2650 \mathrm{~kg} / \mathrm{m}^{3}$ and particle diameter of $13.36 \mu \mathrm{m}$. $\left(\mathrm{d}_{16}=4.50 \mu \mathrm{m}\right.$ and $\left.\mathrm{d}_{84}=35.42 \mu \mathrm{m}\right)$. Two roughness shapes (Cylindrical and Conical) with three various heights (10, 25, and $40 \mathrm{~mm}$ ) 
were used which were made by wood. Length of rough bed was $4 \mathrm{~m}$ (as mentioned, the rough bed starts after $1.5 \mathrm{~m}$ downstream of sluice gate).

The rough bed was made in stagger arrangement. Roughness with $25 \mathrm{~mm}$ height is equivalent with average of $h_{m}$ parameter for smooth bed tests, so greater and smaller heights are were in the jet and wall regions, respectively ( $h_{m}$, jet and wall regions are described in Fig. 1.). Longitudinal and transverse center by center distances of roughness were 75 and $30 \mathrm{~mm}$ respectively. The roughness arrangement was chosen such that three conditions were satisfied: 1-Velocity and concentration profiles near the bed can be measured. 2- Possibility of increasing of conical roughness height and 3- The development process of the current in the streamwise direction can be seen in the experiments.

\section{Flow velocity measurement}

Four vertical velocities (at the 75, 150, 198 and $225 \mathrm{~cm}$ distances from the beginning of the rough bed) were measured with an Ultrasonic Velocity Profiler (UVP) in each test, made by Signal Processing ${ }^{\circledR}$. Data acquisition took approximately $25 \mathrm{~s}$ for each probe position. The UVP transducers had an angle of $25^{\circ}$ looking downstream. For all tests, the length of the sample volume and the emitting frequency were fixed $1.29 \mathrm{~mm}$ and $3.6 \mathrm{MHz}$, respectively.

\section{Flow concentration measurement}

Three rakes of siphons located at the 75, 150 and $225 \mathrm{~cm}$ distances from the beginning of the rough bed were used to obtain sample of concentrations at difference elevations. These samples were used to determine upward-normal profiles of salinity or concentration of suspended sediment. Each rake with 14 siphons was positioned in the center of the transverse axis of flume, so that the center of the first siphon was $0.3 \mathrm{~cm}$ above the bed and the central distance between siphons was fitted to $1.5 \mathrm{~cm}$. The siphons were made of copper tubes with 5 $\mathrm{mm}$ external diameter and $3 \mathrm{~mm}$ internal diameter. The salinity of saline density current samples was measured with EC meter of $\pm 0.1 \mu \mathrm{S}$ accuracy. The collected samples of sediment-laden density current were weighted and dried in an oven to measure suspended sediment concentration.

\section{Experimental parameters}

The $\mathrm{x}$-axis was aligned with the streamwise direction, and the z-axis was perpendicular to the bed. The Reynolds number based on layer thickness, layer-averaged flow velocity and the 
kinematic viscosity of current ranged from 2,200 to 5,600. The dynamic viscosity of fluid mixture $\mu$ was defined as below (Roscoe 1952):

$\mu=\mu_{W}\left(1-1.35 C_{S_{W}}\right)^{-2.5}$

Where $\mathrm{C}_{\mathrm{Sw}}$ is the volume concentration and $\mu_{\mathrm{w}}$ is the dynamic viscosity of ambient fluid.

Fig. 1 shows the main parameters used in the velocity and concentration profiles.

Fig. 1.

The parameters $\mathrm{C}_{\mathrm{av}}, \mathrm{U}_{\mathrm{av}}$ and $\mathrm{h}_{\mathrm{t}}$ were determined from the moment equations introduced by Turner (Turner 1973):

$C_{a v}=\frac{\int_{0}^{\infty} c u d z}{\int_{0}^{\infty} u d z}$

$U_{a v}=\frac{\int_{0}^{\infty} u^{2} d z}{\int_{0}^{\infty} u d z}$

$h_{t}=\frac{\left(\int_{0}^{\infty} u d z\right)^{2}}{\int_{0}^{\infty} u^{2} d z}$

Where $\mathrm{u}$ is locally averaged streamwise flow velocity, $\mathrm{c}$ is concentration of saline or suspended sediment, $\mathrm{z}$ is upward-normal coordinate and $\mathrm{h}_{\mathrm{t}}$ flow layer thickness.

The densimetric Froude number $\left(\mathrm{F}_{\mathrm{rd}}\right)$ and the bulk Richardson number $\left(\mathrm{R}_{\mathrm{ig}}\right)$ are: (Turner 1973)

$$
F_{r d}=\frac{U_{a v}}{\sqrt{g^{\prime} h_{t} \cos \theta}}=\frac{1}{\sqrt{R_{i g}}}
$$

Where the reduced gravitational acceleration is

$$
g^{\prime}=g \frac{\left(\rho-\rho_{w}\right)}{\rho_{w}}
$$

In which $\rho$ is the mixture density, $\rho_{\mathrm{w}}$ the ambient water density and $\mathrm{g}$ is gravitational acceleration. Mixing rate of the ambient fluid in the density current defined as entrainment coefficient $\left(\mathrm{E}_{\mathrm{w}}\right)$ (Parker et al. 1987). 
$E_{W}=\frac{1}{U_{a v}} \frac{\delta U_{a v} h_{t}}{\delta x}$

Table 1 summarizes the characteristic of all experiments. In the table, $\mathrm{C}$ is inlet concentration, $\mathrm{Q}$ inlet flow discharge and $\mathrm{r}$ roughness height. The slopes of the channel bed in all experiments were $0.50,1.25$ and $2 \%$.

Figure 2 shows the body of saline density current and head of sediment-laden density current. A rake of siphons and an UVP probe can be clearly seen in this figure.

Fig. 2.

Table 1.

\section{Experimental results}

\section{Verification of experimentation}

Velocity measurements in the body of the current started with UVP, once the current head reached to the end of flume. A non-dimensional velocity profile of three experiments on the smooth bed is shown in Fig. 3 ( $\mathrm{S}=$ bed slope). Velocity profiles of all tests were similar but are scattered in specific range. The scatter of non-dimensional velocity increased at jet region due to the transitory behavior of the current at its top edge. On the other hand, UVP uses the Doppler shift principle to measure water velocity by receiving the echo reflected from small particles suspended within the flow. Therefore, UVP requires particles in the flow. With increasing $\mathrm{z}$, the amount of suspended particles in the flow is reduced, causing noise. So, the measured data in this region are not accurate enough so that only the lower part of the velocity distributions was retained. Since the friction and bed shear forces in the top and bottom current boundaries influence the suggested profile, the measured velocity profiles can be approximated by patching two different algebraic expressions that are valid in different regions of the flow. One relates to the rigid boundary (wall region) along the bottom (Fig .1), whereas the other relates to the interface or diffusion boundary on the top of the maximum velocity (jet region). In the inner region below the maximum velocity, bottom friction is the main controlling parameter and the appropriate term for the velocity profile is a logarithmic distribution in the density stratified as below (Altinakar et al. 1996):

$$
\frac{u(z)}{u_{m}}=\left(\frac{z}{h_{m}}\right)^{1 / \alpha_{v}}
$$


Where $\mathrm{u}(\mathrm{z})$ is mean streamwise velocity at distance $\mathrm{z}$ above the bed and $\alpha_{\mathrm{v}}$ is empirical exponent.

The effect of friction at the top boundary on the velocity profile is considered by modeling a dense stratified layer of limited thickness between two homogeneous fluids (Nourmohammadi et al. 2011). Accordingly, the velocity profile of jet region is determined by a semi-Gaussain equation (Altinakar et al. 1996):

$\frac{u(z)}{u_{m}}=\exp \left[-\beta_{v}\left(\frac{z-h_{m}}{h_{t}-h_{m}}\right)^{\gamma_{v}}\right]$

Where $\beta_{\mathrm{v}}$ and $\gamma_{\mathrm{v}}$ are empirical exponents.

Fig. 3.

One important step in completing the relation for the velocity profile concerns the constants. Equations (8) and (9) were fitted to the measured velocity profiles in the inner and outer regions using different tests for $\alpha_{v}, \beta_{v}$ and $\gamma_{v}$ determination. Table 2 compares the average of these constants for different beds with those of Altinkar et al. (1996) and Nourmohammadi et al. (2011). Note that their tests were sediment-laden over the smooth bed with inlet Froude number between 1-2.33 and 0.6-3.6 for the Altinkar and Nourmohammadi tests, respectively, while, inlet Froude number over the smooth bed in the present study was between $0.65-0.85$ and $0.30-0.45$ in the saline and sediment-laden density currents, respectively. According to the mentioned table, the greater difference between the constants in the present study with other researches is in the jet region. Froude number for other researches is more than present study and bottom friction is the main controlling parameter in the wall region while jet region is most affected by Froude number. So the most difference for jet region constants between this study and other researches is reasonable. The variations of the constants show that increasing in the roughness height causes that the maximum velocity moves upward. It can be concluded that roughness effect on the sediment-laden density current is more than saline density current. Buoyancy effect is the reason of this behavior. So that the reduced gravitational acceleration (g'), which is causes the body of current stuck to the bed, in the sediment-laden density current is less than saline density current. Therefore when current meets the rough bed, sediment-laden density current separated from the bed easier than saline density current.

Table 2. 


\section{Effect of inlet concentration and bed slope on the flow structure}

We consider for illustrative purposes the case of saline density currents. For a given inlet discharge, the structure of such density currents is controlled by inlet concentration, bed slope and bed roughness. In this study, it was found that for relatively low inlet concentration, bed slope and roughness height equal to $0.5 \%$ and $10 \mathrm{~mm}$, the flow was influenced by bed roughness without any significant backflow. For other experiment conditions, the backflow was formed and steady flow was reached on a longer time.

The effect of inlet concentration on flow structure over smooth bed and conic rough bed is studied for sediment-laden density current (Fig 4). The former shows up-normal profiles for mean velocity $\mathrm{u}$ and local concentration $\mathrm{C}$ at $\mathrm{x}=2.25 \mathrm{~m}$ from the beginning of rough bed. Each experiment had the same bed slope (1.25\%), and inlet concentration varied from 8.2 to $16 \mathrm{gr} / \mathrm{L}$. The inlet discharge is about $1 \mathrm{~L} / \mathrm{s}$ and varied from 0.967 to $1.030 \mathrm{~L} / \mathrm{s}$. It was observed that maximum values of both velocity and local concentration increases with boosting the inlet flow concentration which is causes that the distance from the bed to the point of maximum velocity, $h_{m}$, decreases. But for roughness height $r=25$ and $r=40 \mathrm{~mm}$ this distance is constant. This behavior is because of roughness height effect. Greater roughness causes more ability of flow control, so, does not allow tangible changes in the $h_{m}$.

Fig. 4.

As can be seen in Fig. 4, c and d, local concentration near the bed ( $\mathrm{z}=3 \mathrm{~mm})$ is less than its higher point while we expect that with distance from the bed the local concentration decreases. This behavior is because of the changing of slope of velocity profile plot in the wall region in (Fig. $4 \mathrm{c}$ and d). So increasing roughness height causes more effective roughness and so velocity profile will be most affected. It can be concluded from Fig. 4 that the slope of velocity profile plot in wall region for smooth and rough bed, r=10 mm, is approximately constant. But for greater roughness, it changes, especially near the wall. $\partial \mathrm{u} / \partial \mathrm{z}$ increases at near the bed for these roughness heights and the local gradient Richardson number $\mathrm{Ri}_{\mathrm{gl}}$ will be decreased and entrainment of flow layers will be increased, which leads to reduce in the local concentration near the bed.

The local gradient Richardson number $\mathrm{Ri}_{\mathrm{gl}}$ can be defined as 
$R i_{g l}=-\frac{g(\partial \rho / \partial z)}{\rho(\partial u / \partial z)^{2}}$

Where $\rho$ denotes the local density of the flow. This parameter is a dimensionless ratio scaling the buoyant production or consumption of turbulence divided by the shear production of turbulence. It used to indicate dynamic stability and the formation of turbulence in the stratified flows. When the shear exerted across a density interface is sufficiently large to case the gradient Richardson number to fall the below a critical value of about 0.25 (e.g., (Turner 1973)), Kelvin-Helmholtz waves grow and overturn to produce patches of turbulent mixing. Above the critical value turbulence is damped strongly.

The effect of bed slope increasing on the velocity profiles can be seen in Fig. 5. These experiments were run over smooth and conic rough bed with three heights. For smooth bed and rough bed with $10 \mathrm{~mm}$ height, increasing bed slope causes increasing in the velocity peak which is closer to the bed. Flow thickness also decreases. For rough bed with $25 \mathrm{~mm}$ height there is no significant changes in the maximum velocity and its distance from the bed. This behavior is because of roughness effect on the flow structure. So that the increase in roughness height arise the flow control by the bed rough.

Fig. 5.

\section{Effect of bed roughness on the flow structure}

The effect of bed roughness on profiles of velocity and concentration is illustrated in Fig. 6 . The former shows up-normal profiles for mean velocity $u$ and local concentration $\mathrm{c}$ at $\mathrm{x}=2.25$ $\mathrm{m}$ from beginning of rough bed. Each experiment had the same bed slope (1.25\%) for two roughness shapes, conic and cylindrical, and three roughness height 10, 25 and $40 \mathrm{~mm}$. Also the inlet concentrations and discharges were approximately same for both roughness shapes. It is seen in the figure that maximum velocity value is decreased and displaced upward with increasing of roughness height for cylindrical bed roughness. Density current behavior over the conic rough bed is similar to cylindrical roughness for roughness height 10 and $25 \mathrm{~mm}$. The velocity profiles for these roughness heights are similar. Value of maximum velocity and its distance from the bed is smaller and larger in the conic roughness, respectively. Therefore in these two roughness height, conic shape is more effective than cylindrical. But for conic roughness height $40 \mathrm{~mm}$, value of maximum velocity is greater than the same roughness with height of $25 \mathrm{~mm}$. This behavior is due to lifting phenomenon. When this phenomenon has 
been occurred, much of the density current is accelerated and tends to pass over the roughness, so, effective roughness is decreased. In this roughness height, value of maximum velocity is raised. Fig. 6 provides concentration profiles for plane bed experiments show no inflexion point. While these profiles for rough beds show an inflexion point above bed. So that larger roughness can lead to more distance of inflexion point from the bed and more thickness of body of current. But for conic rough bed with height of $40 \mathrm{~mm}$, there is no significant change in the distance of inflexion point from the bed and thickness of current body. Uniform distribution of concentration profile is resulting from uniform distribution of flow turbulence in the wall region over rough beds. More uniform distribution of flow turbulence stemming from greater roughness.

Fig. 6.

\section{Lifting phenomenon}

The response of the open-channel flow structure to a sudden change of bed roughness is different from buoyancy-laden flows (such as density currents). When there is a change in the bed roughness, the velocity distributions and turbulent characteristics of open-channel flows are expected to vary in both the streamwise and vertical direction due to the roughness discontinuity (Chen and Chiew 2003), as maximum velocity decreases and its distance from the bed increases in the streamwise direction over the rough bed. In the density currents, $\mathrm{g}^{\prime}$, which is causes the body of current stuck to the bed, is too small (its maximum value is 0.108 $\mathrm{m} / \mathrm{s}^{2}$ in this study). So when current meets rough bed, body of current tends to pass over the roughness. Therefore velocity profile was affected by this behavior, which is observed in the present study for the first time, according to the done reviews, and named "Lifting phenomenon". In the present research, this phenomenon has been detected using a detailed examination of the velocity profiles in the streamwise direction.

A clear view of mentioned differences between rough bed flows with and without lifting phenomenon illustrated in Fig. 7 for saline density currents. The figure shows that value of maximum velocity decreases and recedes from the bed in the streamwise direction over the plane bed and $10 \mathrm{~mm}$ height rough bed (where $\mathrm{U}$ is inlet velocity of density current and $\mathrm{X}$ distance from beginning of rough bed $(150 \mathrm{~cm}$ downstream of sluice gate) in the streamwise direction). Thickness of body also increases with moving along the flow. This trend is indicative of the flow development along the streamwise direction. Fig. 7 (d) describes velocity profiles variations over the rough bed with height of $40 \mathrm{~mm}$. The former shows greater velocity peak at distance of $150 \mathrm{~cm}$ from the beginning of rough bed compared with 
velocity profile at $X=75 \mathrm{~cm}$. While on the rough bed we had not expected this behavior. So it can be determined that lifting phenomenon in this longitudinal interval has occurred. Body of current accelerates and tends to pass over the roughness, velocity peak increased and its distance from the bed and thickness of body decreased as a result of small g' and presence of roughness. Moving along the streamwise direction in the Fig. 7 (d) results that velocity peak reducing at $X=198,225 \mathrm{~cm}$. This can be because of disappearance of the initial acceleration of flow, due to lifting phenomenon, and growing of the effective roughness. Detailed analyses of Fig. 7 (d) at $\mathrm{X}=198 \mathrm{~cm}$ has explored that velocity profile is attained shows separation near the bed, where $\partial \mathrm{u} / \partial \mathrm{z} \rightarrow 0$ (As mentioned by Schlichting (1979)). For saline density currents, lifting phenomenon was seen in a number of experiments with the roughness height of $40 \mathrm{~mm}$.

Fig. 7.

The effect of conic rough bed on the sediment-laden density currents is studied in Fig. 8 . From this figure we can see that velocity profile over the plane bed is developed and there is no significant changes in the streamwise direction. While development process of velocity profile can be seen over $25 \mathrm{~mm}$ rough bed. Lifting phenomenon have occurred at interval distance, 198 to $225 \mathrm{~cm}$ and 75 to $150 \mathrm{~cm}$ of 10 and $40 \mathrm{~mm}$ heights of roughness, respectively. In such flows, due to sedimentation, value of g' will more reduced in comparison with saline density currents. So, lifting phenomenon was observed for three heights of roughness in the sediment-laden density currents. For rough bed with $10 \mathrm{~mm}$ height, because of sufficient g' to prevent lifting phenomenon, this behavior has not been observed before section $X=198 \mathrm{~cm}$. As can be seen, after this section, lifting phenomenon has happened, This is stems from sedimentation process of density current along the streamwise direction before section $\mathrm{X}=198 \mathrm{~cm}$ which is causes decreasing in the g'. So mentioned phenomenon has been observed after this section.

Fig. 8.

\section{Criterion of lifting phenomenon}

In a control volume where lifting phenomenon has happened, five parameters used to dimensional analysis: cross-section area of current body A, cross-section area of roughness $A_{r}$, layer-averaged velocity $U_{a v}$, thickness of body $h_{t}$, roughness height $r$ and reduced gravitational acceleration g'. Eq. 11 was extracted by Buckingham theorem. 
$L_{f}=f\left(F_{r d}, A / A_{r}, r / h_{t}\right)$

Where $\mathrm{L}_{\mathrm{f}}$ is parameter of occurrence of lifting phenomenon.

Fig. 9 shows variations of minimum required blockage factor, $\mathrm{A}_{\mathrm{r}} / \mathrm{A}$, against densimetric Froude number to occurrence of lifting phenomenon for saline density currents. As mentioned before, in this type of flows, lifting phenomenon has occurred for $40 \mathrm{~mm}$ height of roughness. This figure provides that greater densimetric Froude number needs greater blockage factor to occurrence of lifting phenomenon. This factor for conic roughness is more than cylindrical rough bed.

Fig. 9.

Fig. 10 illustrates how the minimum required blockage factor varies against densimetric Froude number for sediment-laden density current over three heights and two shapes roughness. This figure indicates that lifting phenomenon requires smaller blockage factor for conic roughness except for roughness with height of $40 \mathrm{~mm}$. This dichotomy of behavior with increasing roughness height is because of roughness shape effect. So that cross-section area of conic roughness with heights of 10 and $25 \mathrm{~mm}$ are less than corresponding cylindrical roughness which is in contrast to the height of $40 \mathrm{~mm}$.

Fig. 10.

\section{Coefficient of entrainment}

Some studies have calculated coefficient of entrainment, such as Fukushima et al. (1985), Ghomeshi (1995) and Parker et al. (1987). The coefficient of ambient fluid entrainment $E_{W}$ was calculated from a finite difference form of Eq. 7 between two sections. The resulted values were plotted then against the Richardson number $\mathrm{Ri}_{\mathrm{g}}$ defined in Eq. 5. Fig. 11 compares calculated $\mathrm{E}_{\mathrm{W}}$ in the present study for sediment-laden density currents over plane bed with those of other studies which show strong similarity with mentioned studies.

Fig. 11.

Values of entrainment coefficient for sediment-laden density currents over smooth and rough beds are shown in Fig. 12. The figure explores that greater roughness causes more $\mathrm{E}_{\mathrm{w}}$. There were two reasons for these variations; (i) greater roughness leads to more sedimentation, (ii) presence of roughness causes increasing of the up-normal gradient of velocity in the velocity profile in the entrainment region, particularly when lifting phenomenon occurs, and leads to a reduction in the gradient of Richardson number, so $\mathrm{E}_{\mathrm{w}}$ grows. The figure also shows that for 
three vary heights of roughness, $E_{\mathrm{w}}$ of flows over conic roughness is more than cylindrical shape. So that greater roughness height leads to most of this difference. This is because of roughness shape effect.

Fig. 12.

\section{Conclusions}

This paper provides a description and analysis of the upward-normal profiles of streamwise flow velocity and concentration of dense underflows over artificial rough beds. A total of 63 sustained saline underflows and 63 turbidity currents were performed over conic and cylindrical rough bed with heights of 10,25 and $40 \mathrm{~mm}$. Three bed slopes and inlet concentration were used. Key results are summarized below.

- The maximum values of both velocity and local concentration increases with increasing inlet flow concentration. The distance from the bed to the point of maximum velocity also decreases, but for roughness height $\mathrm{r}=25$ and $\mathrm{r}=40 \mathrm{~mm}$ this distance is constant. This behavior is because of roughness height effect. Increasing the inlet flow concentration, density current momentum rises, caused higher value of peak velocity in the vertical velocity profile. Therefore, increasing of momentum of flows over beds with larger roughness was controlled better than smaller roughness. So peak value of velocity almost stays constant with increasing in inlet flow concentration.

- Higher values of bed slope result in higher velocity peaks that are closer to bed. On the rough bed with $10 \mathrm{~mm}$ height, the lower layer affected by roughness which mixes the flow, due to raising the position of the velocity peak and making concentration profiles more homogeneous below the peak. The presence of greater roughness tends to displace the velocity peak upward, and renders the near-bed concentration profile more uniform. But for some experiments, local concentration near the bed is less than its high point while we expect that with distance from the bed the local concentration diminishes. This behavior is because of the change in the slope of velocity profile plot in the wall region. For these roughness heights $\partial \mathrm{u} / \partial \mathrm{z}$ increases at near the bed so the local gradient Richardson number $\mathrm{Ri}_{\mathrm{gl}}$ will be decreased which causes more entrainment, so local concentration near the bed will be abated.

- More roughness height leads to less maximum velocity value which has more distance from the bed for cylindrical roughness. Density current behavior over the conic rough bed is similar to cylindrical roughness for roughness height 10 and $25 \mathrm{~mm}$. Value of maximum 
velocity and its distance from the bed is smaller and larger in the conic roughness, respectively. But for conic roughness height $40 \mathrm{~mm}$, this trend was reserved and value of maximum velocity is greater than roughness height $25 \mathrm{~mm}$. This behavior is due to lifting phenomenon.

- In the density currents, g', which is causes the body of current stuck to the bed, is too small. So when current meets rough bed, body of current tends to pass over the roughness. Therefore velocity profile affected by this behavior, which is observed in the present study for the first time, according to the done reviews, and named "Lifting phenomenon". In the present research, this phenomenon has been detected using a detailed examination of the velocity profiles in the streamwise direction.

\section{Acknowledgements}

The staff of the Water Science Engineering faculty of Shahid Chamran University of Ahwaz are gratefully acknowledged. Also the authors gratefully acknowledged professor ShafaieBajestan, Dean of department of Water Structures, and Mr. Zeynivand, the technician of Laboratory of Physical and Hydraulic Models.

\section{Notation}

The following symbols are used in this paper:

$\begin{array}{llll}\mathrm{A} & =\text { cross-section area of flow } & \mathrm{u} & =\text { local-averaged flow velocity } \\ \mathrm{A}_{\mathrm{r}}=\text { cross-section area of roughness } & \mathrm{u}_{\mathrm{m}} & =\text { local-averaged streamwise peak } \\ \mathrm{a} & =\text { reference distance above bed } & \mathrm{u}(\mathrm{z}) & =\text { local-averaged velocity at } \mathrm{z} \\ \mathrm{C} & =\text { inlet concentration } & \mathrm{R}_{\mathrm{ig}} & =\text { gradient Richardson number } \\ \mathrm{C}_{\mathrm{av}}=\text { layer-averaged concentration } & \mathrm{R}_{\mathrm{igl}} & =\text { local gradient Richardson number } \\ \mathrm{C}_{\mathrm{sw}}=\text { volume concentration } & \mathrm{r} & =\text { roughness height } \\ \mathrm{c} & =\text { local-averaged concentration } & \mathrm{S} & =\text { bed slope } \\ \mathrm{c}_{\mathrm{a}}=\text { concentration at a } & \mathrm{X} & =\text { distance of sampling section from } \\ \mathrm{E}_{\mathrm{w}}=\text { coefficient of entrainment } & \mathrm{x} & =\text { streamwise coordinate } \\ \mathrm{F}_{\mathrm{rd}}=\text { densimetric Froude number } & \mathrm{z} & =\text { upward-normal coordinate } \\ \mathrm{g} & =\text { gravitational acceleration } & \alpha_{\mathrm{v}}, \beta_{\mathrm{v}}, \gamma_{\mathrm{v}} & =\text { empirical exponents } \\ \mathrm{g}^{\prime}=\text { reduced gravitational acceleration } & \mu & =\text { dynamic viscosity of fluid mixture } \\ \mathrm{h}_{\mathrm{m}}=\text { distance from the bed where } \mathrm{u}_{\mathrm{m}} & \mu_{\mathrm{w}} & =\text { dynamic viscosity of fluid ambient } \\ \mathrm{h}_{\mathrm{t}}=\text { flow layer thickness } & \rho & =\text { layer-averaged flow density } \\ \mathrm{Q}=\text { inlet discharge } & \rho_{\mathrm{w}} & =\text { density of fluid ambient fluid (water) } \\ \mathrm{U}_{\mathrm{av}}=\text { layer-averaged flow velocity } & \theta & =\text { bed slope angle }\end{array}$




\section{References}

Altinakar, M.S., Graf, W.H. and Hopfinger, E.J. 1996. Flow structure in turbidity current. Journal of Hydraulic Research, 34(5): 713-718.

Bournet, P.E., Dartus, D., Tassin, B. and Vincon-Leite, B. 1999. Numerical investigation of plunging density current. Journal of Hydraulic Engineering, 125(6): 584-594.

Chen, X. and Chiew, Y.M. 2003. Response of velocity and turbulence to sudden change of bed roughness in open-channel flow. Journal of Hydraulic Engineering, 129(1): 35-43.

Ellison, T.H. and Turner, J.S. 1959. Turbulent entrainments in stratified flows. Journal of Fluid Mechanics, 6(3): 423-448.

Ezz, H., Cantelli, A. and Imran, J. 2013. Experimental modeling of depositional turbidity currents in a sinuous submarine channel. Journal of Sedimentary Geology, 290: 175-187.

Fukushima, Y., Parker, G. and Patin, H.M. 1985. Prediction of ignitive turbidity currents in scripps submarine canyon. Journal of Marine geology, 67: 55-81.

Garcia, M.H. and Parker, G. 1993. Experiments on the entrainment of sediment into suspension by a dense bottom current. Journal of Geophysical Research, 98(C3): 4793-4807.

Ghomeshi, M. 1995. Reservoir sedimentation modeling. Ph.D. Thesis, Department of Civil and Mining Engineering, University of Wollongong, Australia.

Imran, J., Kassem, A. and Khan, S.M. 2004. Three-dimensional modeling of density current. I. Flow in straight confined and unconfined channels. Journal of Hydraulic Research, 42(6): 578-590.

Islam, M.A. and Imran, J. 2008. Experimental modeling of gravity underflow in a sinuous submerged channel. Journal of Geophysical Research, 113(C7).

Kubo, Y. 2004. Experimental and numerical study of topographic effects on deposition from twodimensional, particle-driven density currents. Journal of Sedimentary Geology, 164: 311-326.

Linden, P.F. and Simpson, J.E. 1986. Gravity-driven flows in a turbulent fluid. Journal of Fluid Mechanics, 172: 481-497.

Nourmohammadi, Z., Afshin, H. and Firoozabadi, B. 2011. Experimental observation of the flow structure of turbidity currents. Journal of Hydraulic Research, 40(2): 168-177.

Oehy, C.D., Cesar, G.D. and Schleiss, A.J. 2010. Effect of inclined jet screen on turbidity current. Journal of Hydraulic Research, 48(1): 81-90.

Oshaghi, M.R., Afshin, H. and Firoozabadi, B. 2013. Experimental investigation of effect of obstacles on the behavior of the density currents. Canadian Journal of Civil Engineering, 40: 343-352. 
Parker, G., Garcia, M., Fukushima, Y. and Yu, W. 1987. Experiments on turbidity currents over an erodible bed. Journal Hydraulic Research, 25(1): 123-147.

Roscoe, R. 1952. The viscosity of suspensions of rigid spheres. British Journal of Applied Physics, 3(8): 267-269.

Sequeiros, O.E., Spinewine, B., Beaubouef, R.T., Sun, T., Garcia, M.H. and Parker, G. 2010. Characteristics of velocity and excess density profiles of saline underflows and turbidity currents flowing over a mobile Bed. Journal Hydraulic Engineering, 136(7): 413-433.

Schlichting, H. 1979. Boundary-Layer theory. McGraw-Hill publication.

Simpson, J.E. 1982. Gravity currents in the laboratory, atmosphere and ocean. Annual Review of Fluid Mechanics, 14: 213-234.

Toniolo, H., Parker, G. and Voller, V. 2007. Role of ponded turbidity currents in reservoir trap efficiency. Journal of Hydraulic Engineering, 133(6): 579-595.

Turner, J.S. 1973. Buoyancy effects in fluids. Cambridge University Press. U.K. 
Table 1. Inlet conditions and other characteristics of the experiments

\begin{tabular}{cccccccc}
\hline \multirow{2}{*}{ Series } & $\begin{array}{c}\text { Number } \\
\text { of tests }\end{array}$ & $\begin{array}{c}\text { Roughness } \\
\text { shape }\end{array}$ & $\mathbf{r}(\mathbf{m m})$ & \multicolumn{2}{c|}{ Saline density current } & \multicolumn{2}{c}{ Sediment-laden density current } \\
\cline { 5 - 8 } & 9 & Smooth bed & ----- & $10.67-20.84$ & $0.937-1.002$ & $8.2-17.0$ & $0.967-1.060$ \\
\hline 1 & 9 & Conical & 10 & $10.26-21.80$ & $0.975-1.108$ & $6.8-16.0$ & $0.961-1.058$ \\
2 & 9 & Conical & 25 & $10.41-20.68$ & $0.980-1.010$ & $8.0-16.7$ & $0.975-0.997$ \\
3 & 9 & Conical & 40 & $10.72-20.41$ & $0.966-1.037$ & $9.6-19.2$ & $0.975-1.025$ \\
4 & 9 & Cylindrical & 10 & $10.04-20.51$ & $0.990-1.012$ & $6.0-16.8$ & $0.992-1.039$ \\
5 & 9 & Cylindrical & 25 & $11.09-21.42$ & $0.960-1.066$ & $7.0-18.2$ & $0.990-1.055$ \\
6 & 9 & Cylindrical & 40 & $11.25-20.84$ & $0.986-1.046$ & $9.2-21.2$ & $0.997-1.030$ \\
7 & 9 & & & & & & \\
\hline
\end{tabular}

Table 2. Constants of equations (8) and (9)

\begin{tabular}{|c|c|c|c|c|c|c|c|}
\hline & & \multicolumn{3}{|c|}{ Saline density current } & \multicolumn{3}{|c|}{ Sediment-laden density } \\
\hline & & $\boldsymbol{\alpha}_{\mathrm{v}}$ & $\boldsymbol{\beta}_{\mathrm{v}}$ & $\gamma_{\mathrm{v}}$ & $\boldsymbol{\alpha}_{\mathrm{v}}$ & $\boldsymbol{\beta}_{\mathrm{v}}$ & $\gamma_{\mathrm{v}}$ \\
\hline $\begin{array}{l}\text { Nourmohammadi et al. } \\
\text { (2011) tests }\end{array}$ & Smooth bed & & ----- & & 5.80 & 0.60 & 2.70 \\
\hline \multirow[t]{4}{*}{ Altinkar et al. (1996) } & Smooth bed & & & & 6.00 & 1.40 & 2.00 \\
\hline & Smooth bed & 5.93 & 2.00 & 2.04 & 6.70 & 2.10 & 1.47 \\
\hline & Conical, $10 \mathrm{~mm}$ & 3.83 & 1.79 & 1.59 & 2.92 & 1.71 & 1.34 \\
\hline & Conical, $25 \mathrm{~mm}$ & 3.01 & 1.69 & 1.80 & 1.66 & 1.40 & 1.64 \\
\hline \multirow[t]{4}{*}{ Present study } & Conical, $40 \mathrm{~mm}$ & 1.99 & 1.73 & 1.72 & 1.20 & 1.35 & 1.78 \\
\hline & Cylindrical, $10 \mathrm{~mm}$ & 4.64 & 2.01 & 1.44 & 2.34 & 1.54 & 1.35 \\
\hline & Cylindrical, $10 \mathrm{~mm}$ & 2.68 & 1.32 & 2.05 & 1.66 & 1.38 & 1.51 \\
\hline & Cylindrical, $10 \mathrm{~mm}$ & 2.04 & 1.32 & 2.18 & 1.15 & 1.23 & 1.70 \\
\hline
\end{tabular}


Fig. 1. Main parameters used in the velocity and concentration profiles

Fig. 2. Laboratory photos of (a) body of saline density current and (b) head of sediment-laden density current

Fig. 3. Dimensionless velocity profile (a) wall region (b) jet region

Fig. 4. Influence of the inlet concentration on the local concentration and velocity profiles; (a) smooth bed; (b) conic rough bed $r=10 \mathrm{~mm}$; (c) conic rough bed $\mathrm{r}=25 \mathrm{~mm}$; (d) conic rough bed $\mathrm{r}=40 \mathrm{~mm}$

Fig. 5. Influence of the bed slope on the velocity profiles; (a) smooth bed; (b) conic rough bed $\mathrm{r}=10 \mathrm{~mm}$; (c) conic rough bed $r=25 \mathrm{~mm}$; (d) conic rough bed $r=40 \mathrm{~mm}$

Fig. 6. Influence of the bed roughness on the flow structure; (a) Conic roughness; (b) Cylindrical roughness

Fig. 7. Velocity profiles in the streamwise direction of saline density current (Cylindrical roughness, $\mathrm{S}=2 \%$ ); (a) Smooth bed, $C=19.2 \mathrm{gr} / \mathrm{L}, \mathrm{Q}=0.978 \mathrm{~L} / \mathrm{s}$; (b) $\mathrm{r}=10 \mathrm{~mm}, \mathrm{C}=19.8 \mathrm{gr} / \mathrm{L}$, $\mathrm{Q}=1.005 \mathrm{~L} / \mathrm{s} ;$ (c) r=25 mm, C=20.2 gr/L, $Q=1.021 \mathrm{~L} / \mathrm{s} ;$ (d) r=40 mm, C=20.8 gr/L, $Q=1.010 \mathrm{~L} / \mathrm{s}$

Fig. 8. Velocity profiles in the streamwise direction of sediment-laden density current (Conic roughness, $\mathrm{S}=0.5 \%$ ); (a) Smooth bed, $\mathrm{C}=17.0 \mathrm{gr} / \mathrm{L}, \mathrm{Q}=1.039 \mathrm{~L} / \mathrm{s}$; (b) $\mathrm{r}=10 \mathrm{~mm}, \mathrm{C}=14.0 \mathrm{gr} / \mathrm{L}$, $\mathrm{Q}=1.058 \mathrm{~L} / \mathrm{s}$; (c) r=25 mm, C=13.6 gr/L, $Q=0.979 \mathrm{~L} / \mathrm{s}$; (d) r=40 mm, C=15.2 gr/L, $Q=1.016 \mathrm{~L} / \mathrm{s}$

Fig. 9. Variations of blockage factor against densimetric Froude number for saline density current

Fig. 10. Variations of blockage factor against densimetric Froude number for sediment-laden density current; filled points: conic roughness; empty points: cylindrical roughness

Fig. 11. Comparison of calculated $E_{W}$ in the present study for sediment-laden density currents over plane bed with those of other studies

Fig. 12. Values of $E_{W}$ for sediment-laden density currents over smooth and rough beds; (a) conic rough bed; (b) cylindrical rough bed 

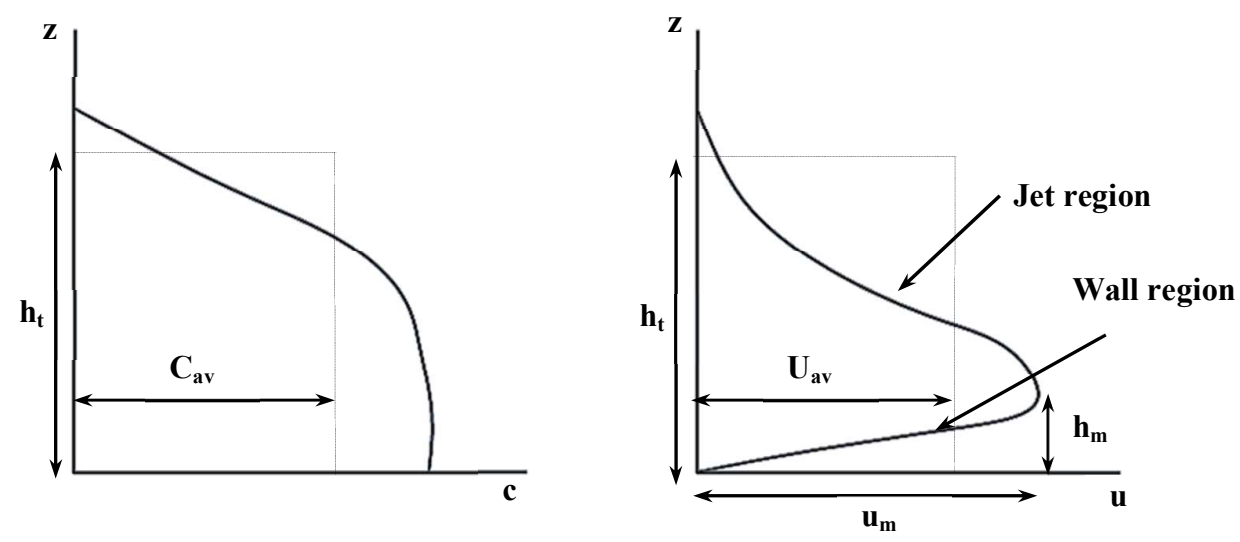

Fig. 1. 


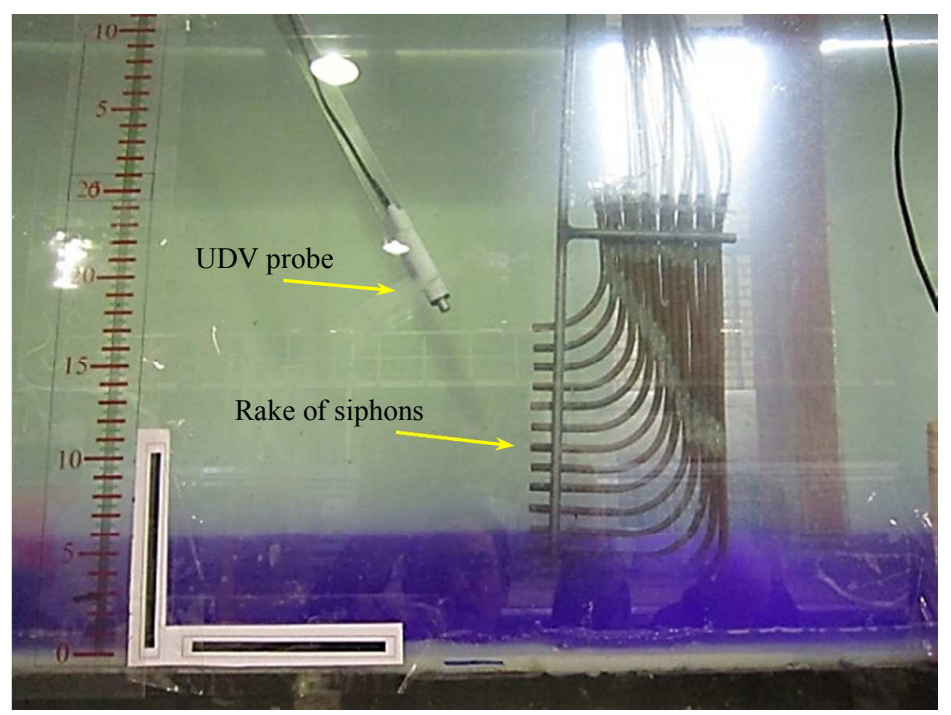

(a)

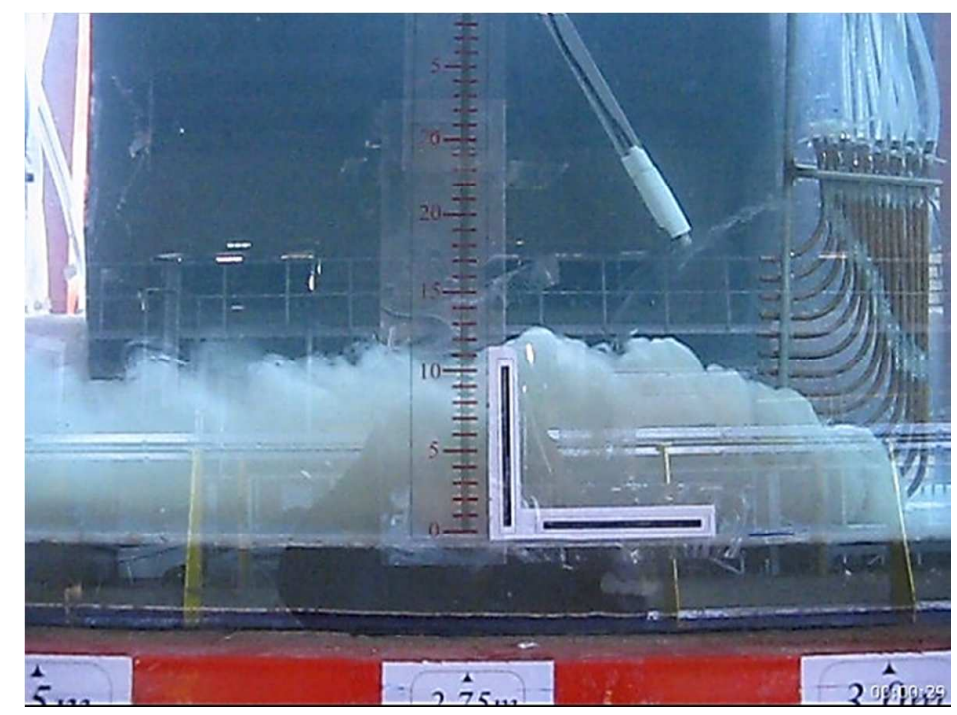

(b)

Fig. 2. 


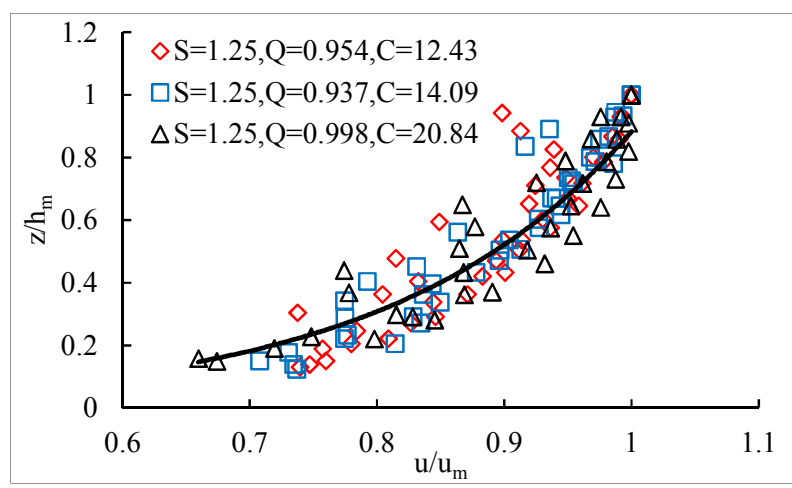

(a)

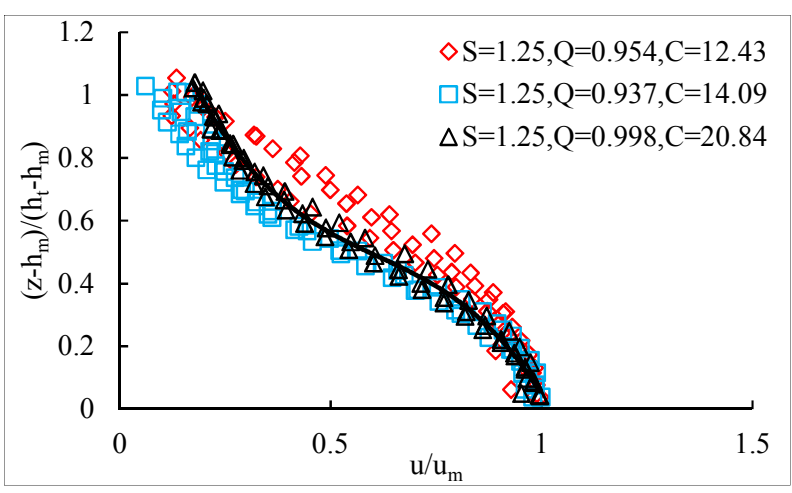

(b)

Fig. 3. 

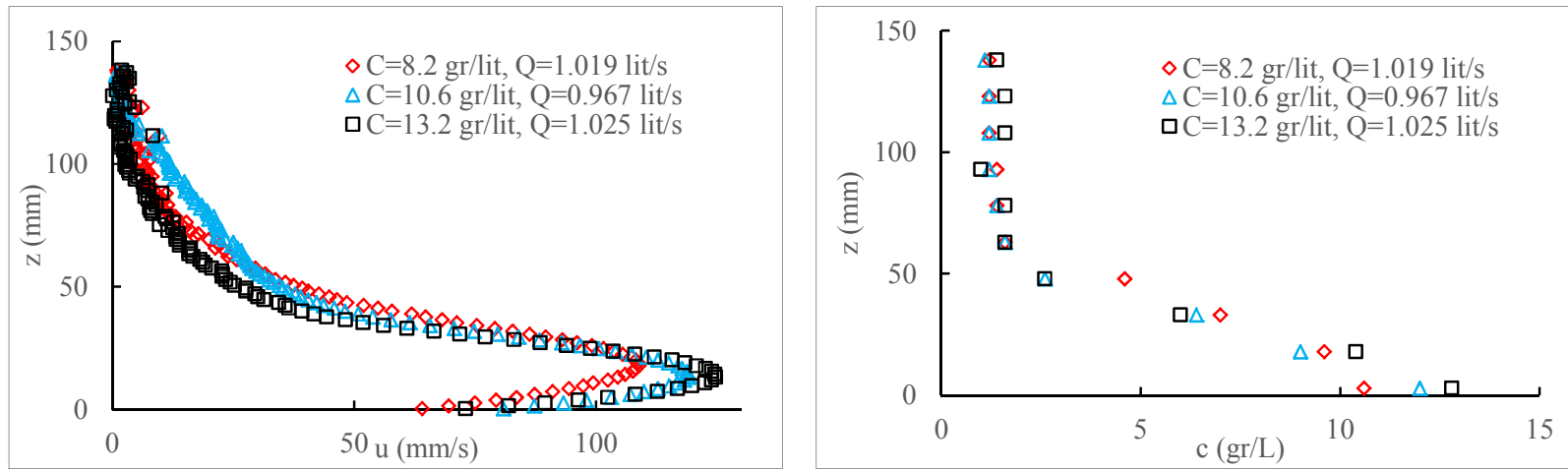

(a)
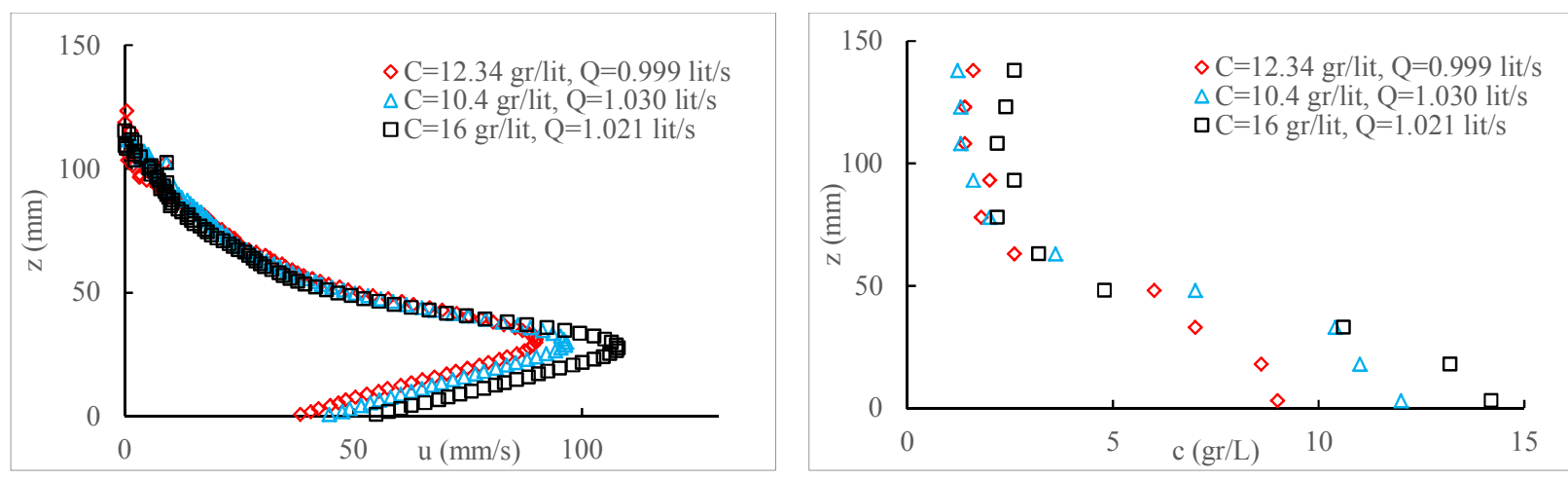

(b)
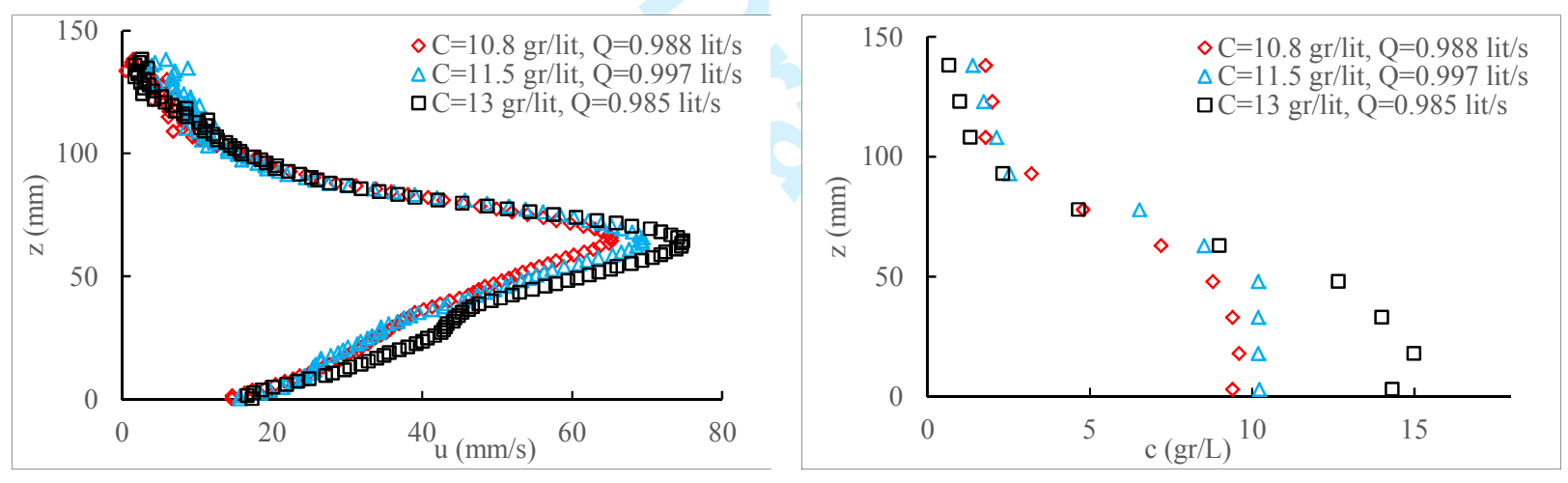

(c)
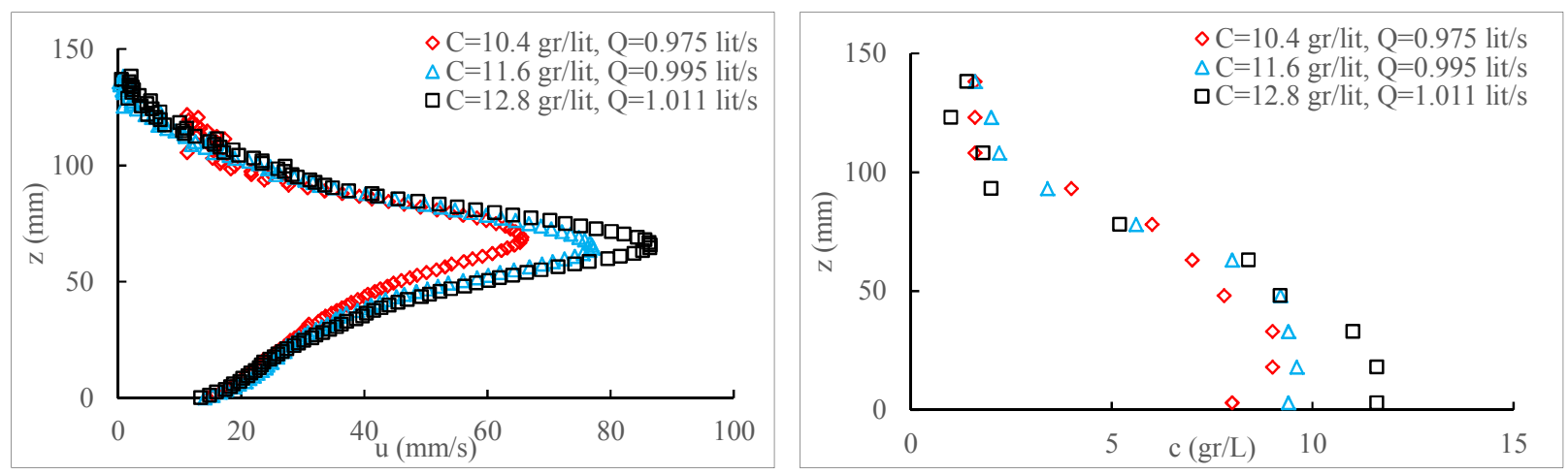

(d)

Fig. 4. 


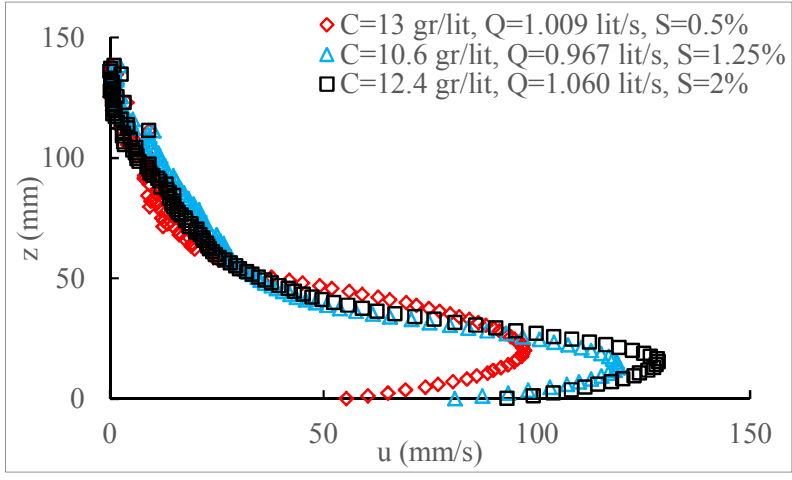

(a)

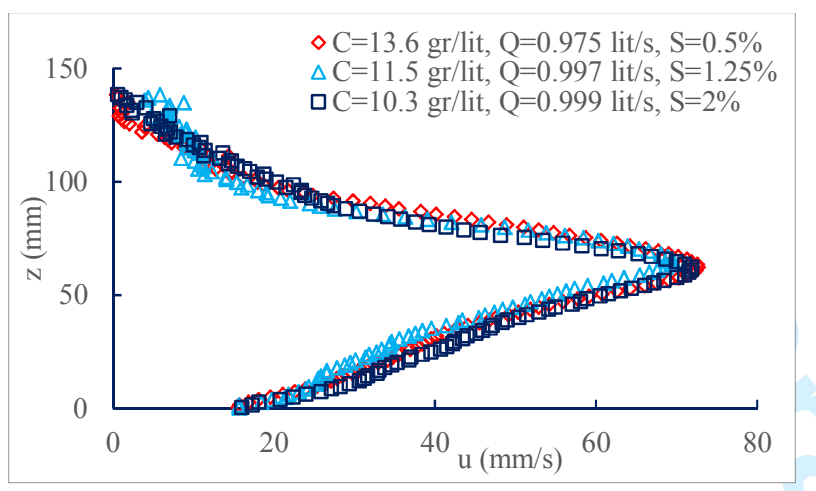

(c)

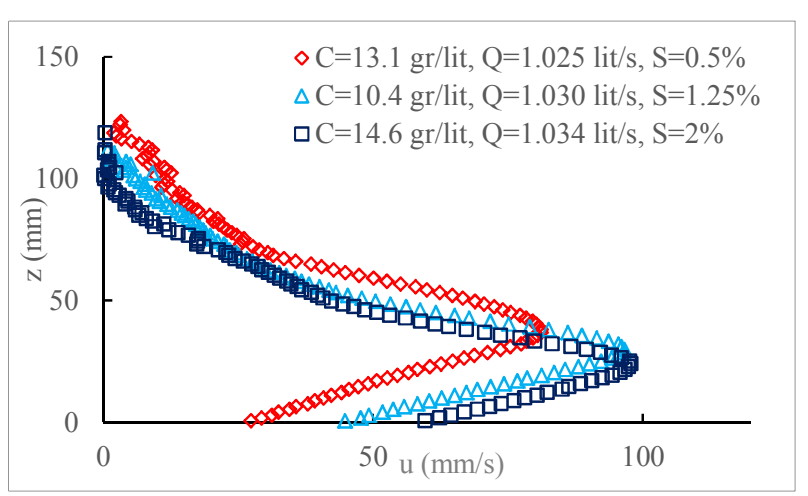

(b)

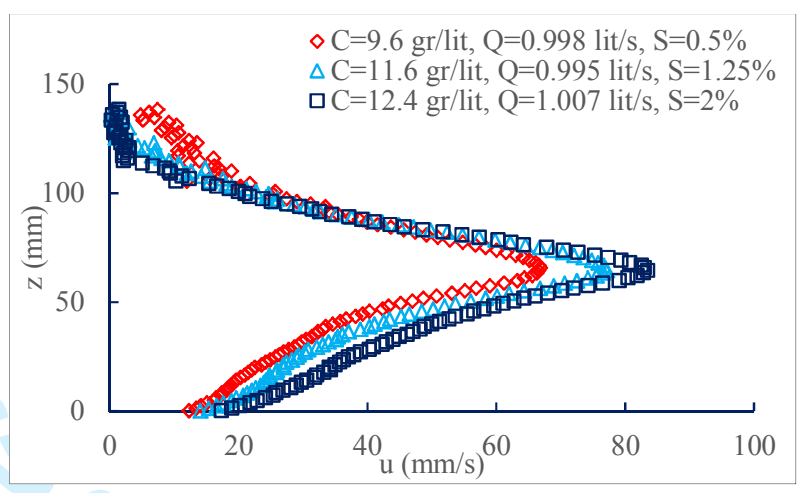

(d)

Fig. 5. 

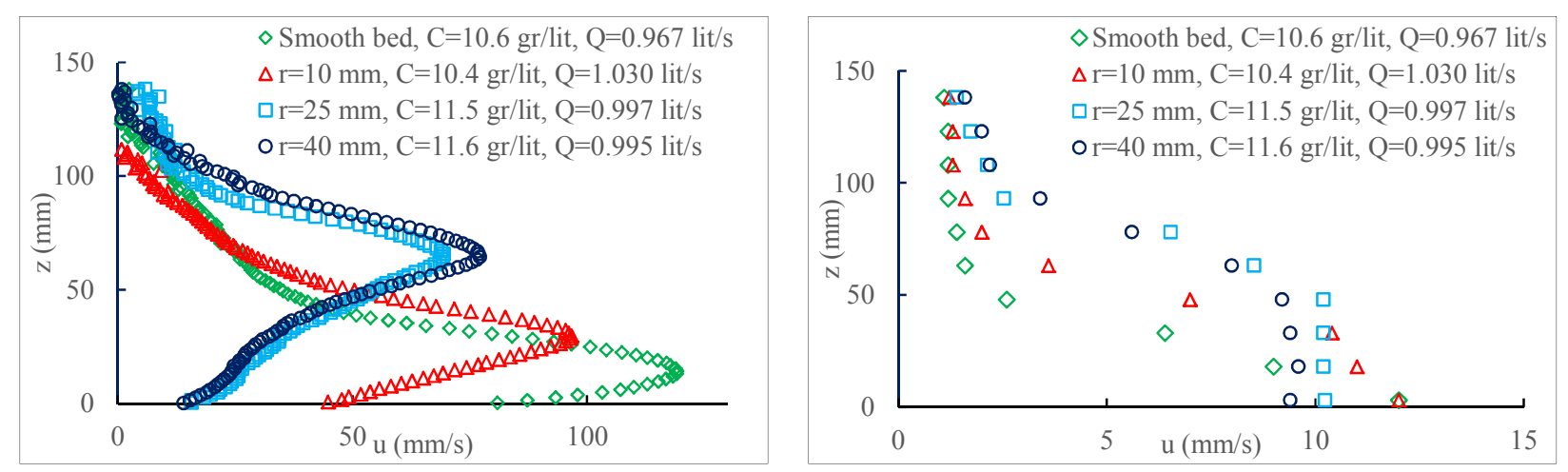

(a)
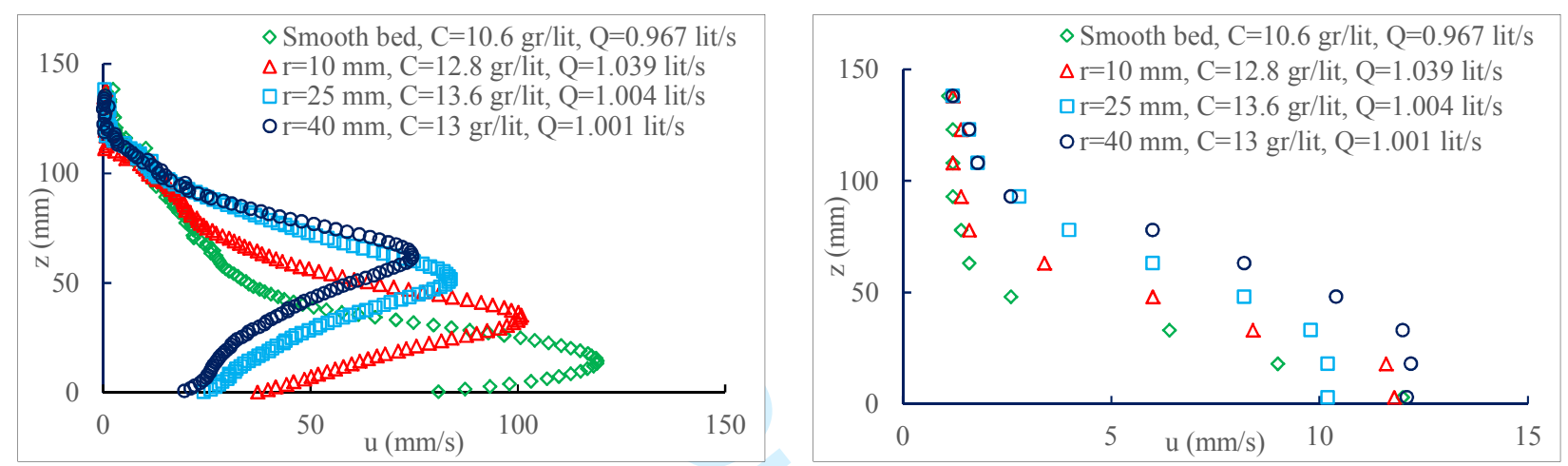

(b)

Fig. 6. 


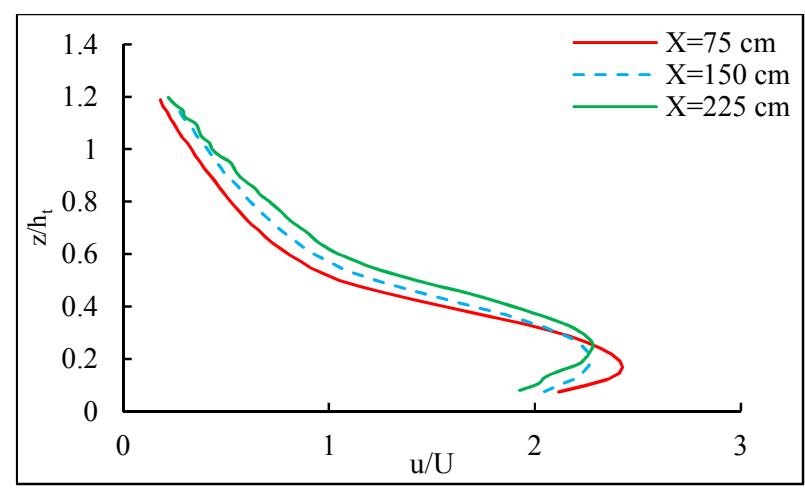

(a)

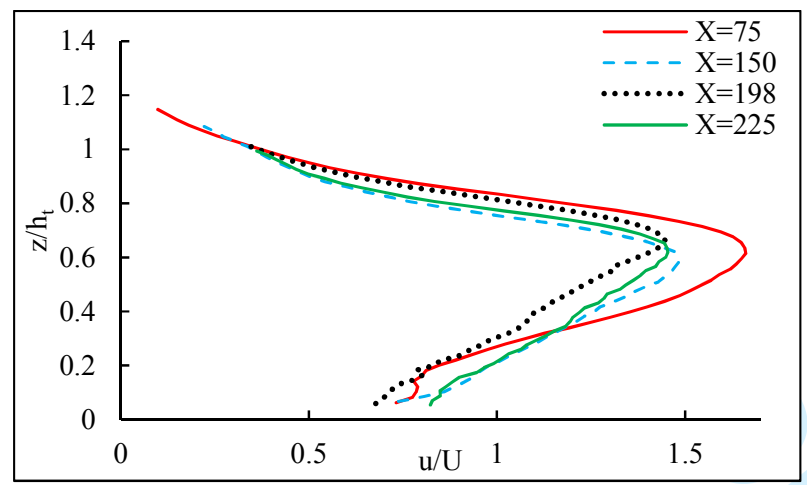

(c)

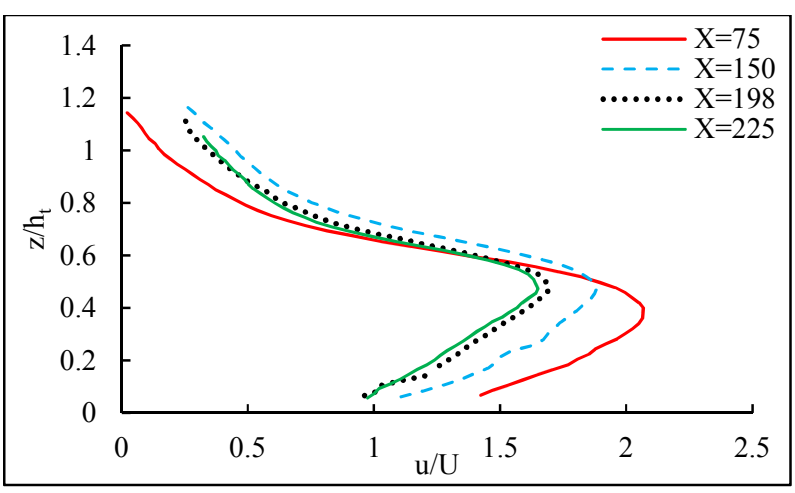

(b)

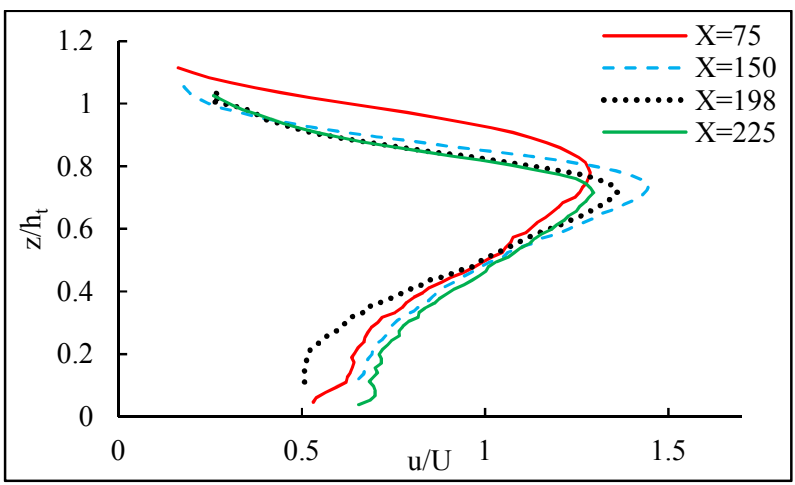

(d)

Fig. 7. 


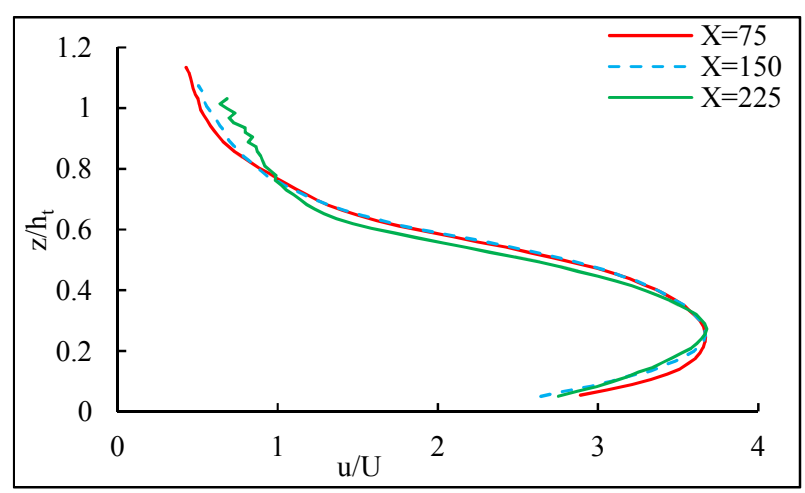

(a)

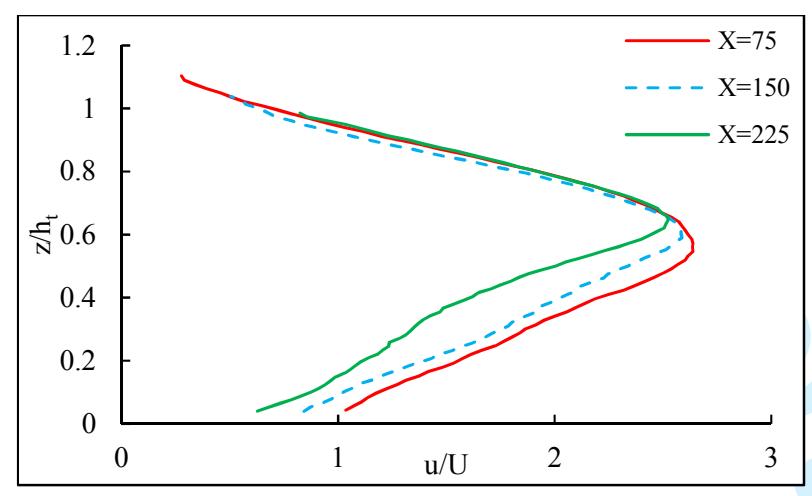

(c)

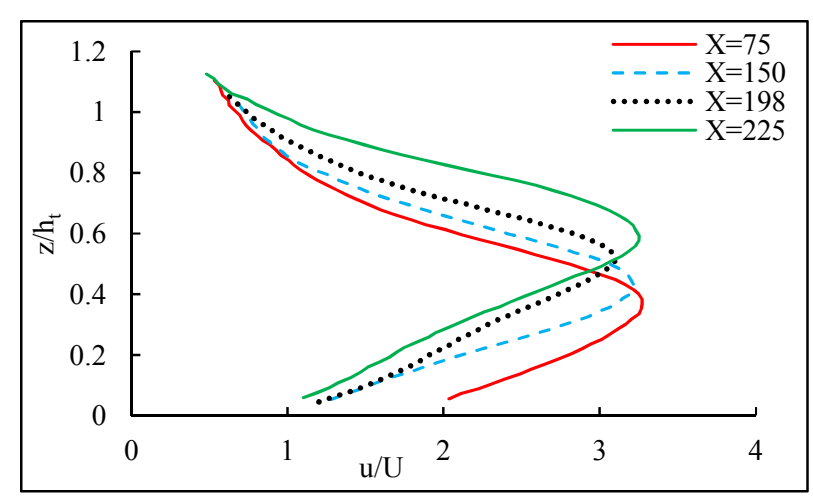

(b)

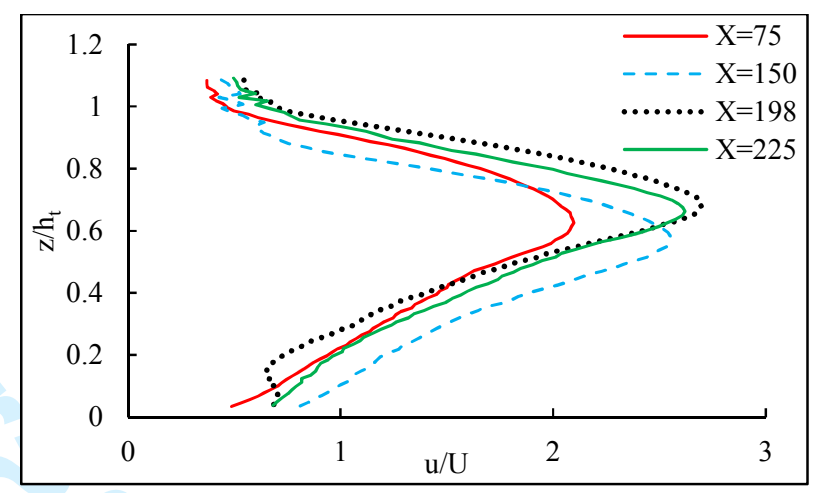

(d)

Fig. 8. 


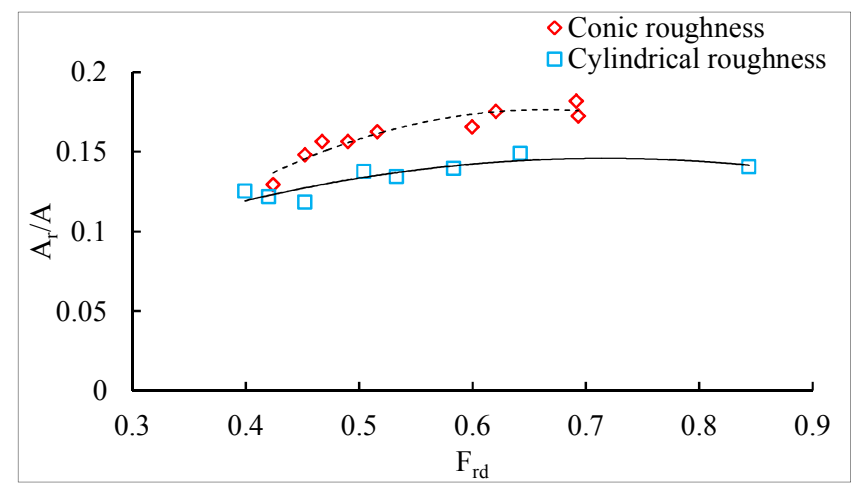

Fig. 9. 


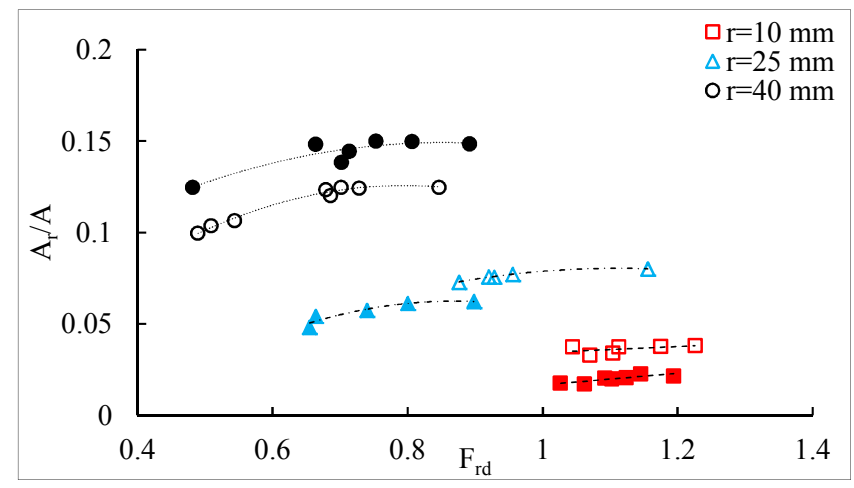

Fig. 10. 


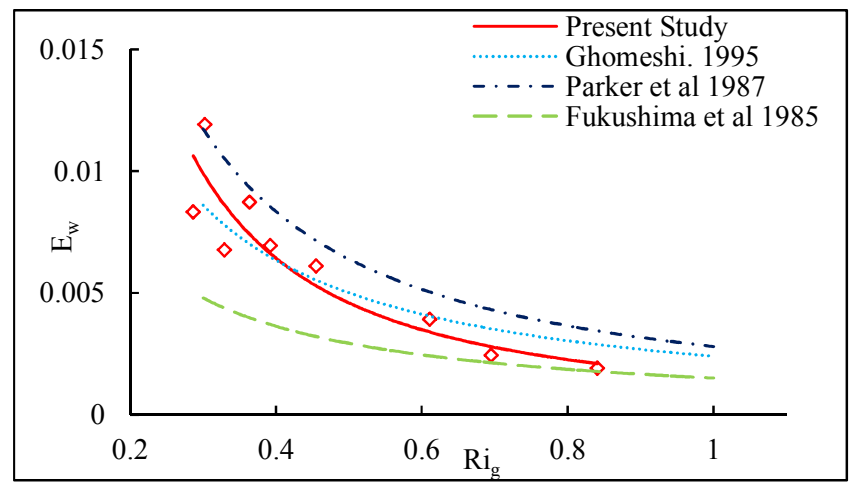

Fig. 11. 


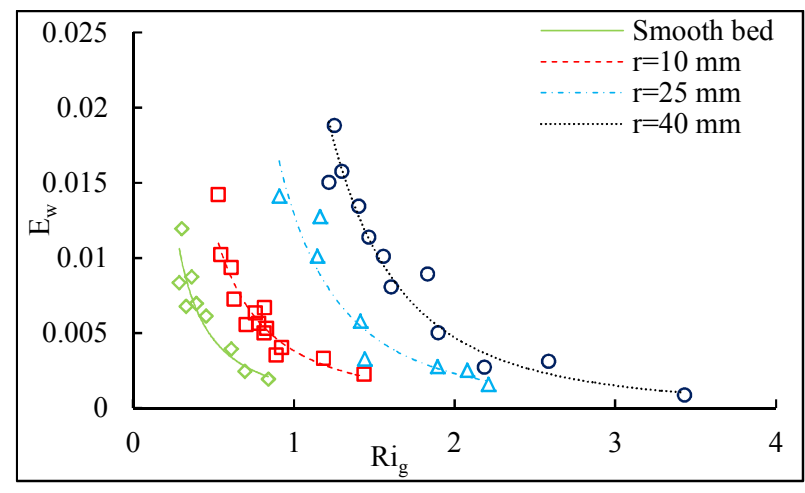

(a)

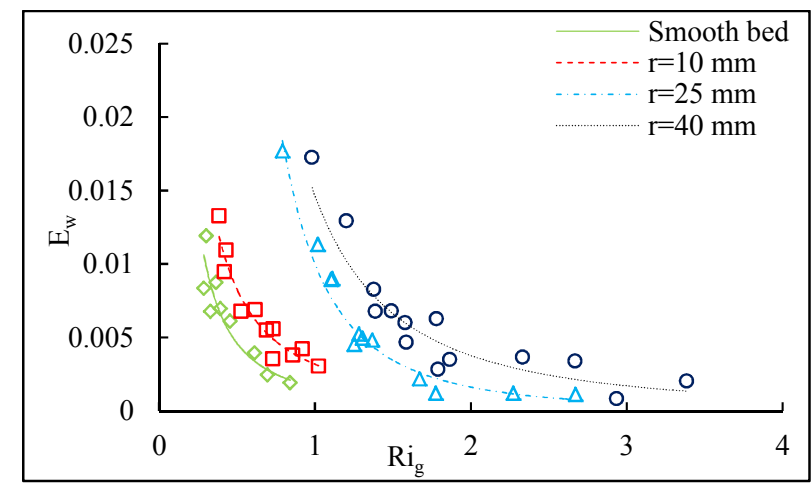

(b)

Fig. 12. 